\title{
Spatial-temporal model of engagement of participants of educational activity in the digital educational environment
}

\author{
L.M. Popov ${ }^{1 *}$, and P.N. Ustin ${ }^{2}$ \\ ${ }^{1}$ Institute of Psychology and Education of Kazan (Volga region) Federal University, Kazan, Russia \\ ${ }^{2}$ Institute of Psychology and Education of Kazan (Volga region) Federal University, Kazan, Russia
}

\begin{abstract}
In the context of the COVID-19 pandemic, the educational process has acquired a virtual character, when the role of technical teaching tools that mediate the real interaction of students with the teacher has sharply increased. The conditions for creating an engagement effect have changed and there is a need to study the phenomenon of engagement and its psychological mechanisms. The main aspects of an engagement manifestation that represent the spatial part of the model are shown: cognitive, emotional, behavioral, activity, motivational, sociopsychological and physical. The novelty of the spatial-temporal model is that it involves all the spatial factors that are included in the main temporal phases of activation of engagement: preparatory, active, evaluation and correction. The long-term and short-term options for using the engagement model with their methods of implementation, expected results and realization mechanisms are proposed. The implementation of the shortterm version of the engagement model is carried out through a system of digital monitoring of emotional and cognitive reactions of a person in a digital environment. The possibility of managing and self-managing students' engagement in educational activities in a digital environment is shown.
\end{abstract}

\section{A problem statement}

The relevance of studying the phenomenon of engagement in the digital educational environment was clearly manifested in the period of COVID-19, when distance learning replaced traditional contact forms of learning. The main difference between the work of a teacher with students in the context of a pandemic is the transition from direct contact to indirect (virtual) contact. In the traditional version of training, the effect of engagement was realized through direct contact between the teacher and the students. Information saturation during classes was carried out at the audiovisual level of perception with the use of emotional accompaniment and intonation influence. The possibility of direct contact

\footnotetext{
* Corresponding author: prof-ped.gpa@mail.ru
} 
remained after the training session, when the student asked spontaneous questions and began a discussion with the teacher.

The educational process in the context of the pandemic has acquired a distant character, while the role of technical teaching tools that mediate the real interaction of students with the teacher has increased dramatically. In the first place, the need to digitalize the educational material has come out, which allows students to master it, not limited to a certain time and a certain space. The information saturation of the student has become more extensive. At the same time, emotional-intonational interaction, as the main way of inspiring influence, has become extremely limited. The conditions for creating the effect of engagement have changed markedly, and there is a need to study the phenomenon of engagement, its psychological mechanisms, and the strategies used by teachers and students in the context of digital learning. Finally, the material and teaching experience accumulated by researchers encourages the creation of different models to achieve the effect of student and teacher engagement.

\subsection{The objective of the work}

The purpose of the study is to theoretically determine the main contours of the model of engagement of participants of educational activity in the context of distance (digital) learning. This purpose includes solving the following tasks: to consider the main characteristics of the phenomenon of engagement as a necessary link in the system of interaction of participants of educational activity; to identify the variety of types (forms, aspects, components) of engagement as spatial elements of the general model; to distinguish main temporal phases of activation of engagement which will include all of the listed spatial manifestations; to identify possible strategies of participants in the educational process (teachers and students) in organizing opportunities for engagement.

\section{Results of the research}

The method of theoretical analysis of literary sources is used as the leading method. The theoretical and methodological basis for the study of the engagement of participants of educational activity is formed by the positions of the subject-activity approach (S.L. Rubinstein, A.N. Leontiev, A.V. Brushlinsky, E.A. Sergienko), which assumes to consider the student and teacher as actors of the educational process and the main positions of the systematic approach to the study of the components of engagement in their unity and interconnection (P.K. Anokhin, B.F. Lomov, V.A. Barabanshchikov).

\subsection{The theoretical foundations of the spatial-temporal model of engagement}

As a result of the theoretical analysis of literary sources, the following characteristics of the phenomenon of engagement are established: emotional and energetic (E. Klinger [1], L.I. Sokolova, E.S. Mishchenko and S.V. Ponomarev [2], M.Yu. Kondratyev [3], A.M. Kustubaeva and A.T. Kamzanova [4], etc.), interest and immersion in what is happening (A.B. Bakker and Y. Wang [5], J.W. Newstrom [6], C. Truss et al. [7], etc.), the system of external and internal forces to achieve the set goals (T.Yu. Bazarov [8]). In general, engagement is a system of interacting actors that reflects the state and process of energetic involvement of its participants in joint activities, taking into account the determination of the process by external and internal factors. In the context of educational activity - this is the state and process of involvement of actors in multi-level joint activities for the transfer, 
reception, assimilation and production of socio-cultural experience, mediated by external and internal determinants.

Among the types, forms, aspects, and components of engagement, cognitive, emotional, behavioral, and motivational engagement are most often mentioned. Physical, value, sociopsychological, and activity engagement are less frequently mentioned. All of them cover the external and internal psychological space of the activity of the actor of educational activity.

Cognitive engagement is one of the main factors of success of actors in educational and professional activities (A. Hollingshead, P. Williamson and C. Carnahan [9], K. Xie, V.W. Vongkulluksn, L. Lu and S.L. Cheng [10], R. Böheim, T. Urdan, M. Knogler and T. Seidel [11], B.D. Jones, D. Carter [12], etc.). It is represented by direct and indirect characteristics. Direct characteristics are associated with maximizing a person's cognitive abilities, including focus, memory, creative thinking (S.R. Harper and S.J. Quaye [13]), employee beliefs, and working conditions (W.A. Kahn and E.D. Heaphy [14]). Indirect characteristics include ideas about education, the degree of its need for professional development, the educational institution, the benefits, accessibility and quality of education (N.V. Kiseleva [15]).

Emotional engagement as one of the constructs of student engagement in academic activities and a factor of their academic success is also widely represented in modern studies (K. Fujiwara[16], A. Hollingshead, P. Williamson and C. Carnahan [9], Regueiro et al. [17], J. Reeve, S.H. Cheon, H. Jang [18], N.A. Smith, J.L. Brown, T. Tran, C. SuárezOrozco [19]). In professional activity, engagement is understood as a positive or negative attitude towards the company, management (W.A. Kahn and E.D. Heaphy [14]), when a person likes or dislikes his job (S.R. Harper and S.J. Quaye [13]), as well as dedication and attractiveness of the chosen profession (N.V. Kiseleva [15]).

Behavioral engagement is considered in the context of educational activities and is given as externally marked characteristic of activity: readiness to participate in the educational process, to attend classes, to follow the instructions of the teacher (S.R. Harper and S.J. Quaye [13], Regueiro et al. [17], R. Böheim et al. [11]; B.D. Jones and D. Carter [12]), to make additional efforts and to get in touch (N.V. Kiseleva [15]). It should be noted that this type of engagement also includes the activity of all participants of educational process. For example, the teacher's activity in finding ways to increase the interest of students (N.V. Kiseleva [15]). Accordingly, the model of engagement should be considered as a two-way process of activity, including the participation of both the teacher and the student.

In the traditional interpretation, the category of behavior is understood broadly and includes both external and internal activity of the person. In our opinion, the external manifestation of activity, which can be stated visually, should be associated with the term "behavior", which is presented above. However, such visualization does not make it possible to explain the deep content of the activity (and subsequently to manage such activity). Therefore, in order to characterize the content side of the activity and the mechanisms involved, it becomes necessary to highlight the activity aspect of engagement.

Activity engagement is considered as an individual's participation in an activity (M. McAllister [20]) and as an absorption in an activity (K. Shaw [21]), when its creative, transformative nature is maintained by student constructing his own activity, his own educational role (E.R. Kahu [22]), where students are in dialogue with the teacher not only assimilate knowledge, but also produce and apply it (A. McCulloch et al [23]).

Motivational engagement is considered as internal driving force: motivation to study (Y.-F. Chang and B.-L. Cherng [24], Chen et al. [25]) and motivation to work (T.O. Solomanidina, V.G. Solomanidin [26], T.Yu. Bazarov [8]), when the actor feels an interest in learning and a desire to contribute to this process; a willingness to make extra efforts, not 
limited to the job description, in achieving results that are significant for the company (M.I. Magura [27]). Here we present an understanding of the internal motivation of participants, first of all, in the work activity, which in other terms is considered as self-determination. According to the system approach, the characteristic "engagement" also includes external incentives (conditions), which is also applicable to educational activities (N.V. Kiseleva [15]).

Socio-psychological engagement based on the analysis of a number of works (K. Xie [10], E.G.T. Becerra and V. Reynoso-Alcántara [28], R.L. Altman [29]) characterizes the presence of interactions: "student-teacher", "student - other students", "student - university (its environment)". This characteristic of engagement allows us to attribute this aspect to the methodological approach of S.L. Rubinstein (L.M. Popov and P.N. Ustin [30]) and his followers, when any effect that occurs in the interaction of actors is integrated into the "Man-World" system, where a person is considered as an actor of contemplation and transformation of the surrounding world.

Physical engagement is defined by the measure of effort, the measure of physical and mental energy, the willingness to demonstrate "super-strength" to perform the work of achieving goals from outside or from within (M.I. Magura [27], A.W. Astin [31]), it is always the ability to take "one step forward" from the obligations (W.A. Kahn and E.D. Heaphy [14])). The phenomenon of the energy component in the performance of activities was justified by V.M. Bekhterev more than a century ago (V.M. Bekhterev [32]).

Within the framework of a probabilistic psychological model of the engagement of participants of educational activity on the basis of generalization of the considered material and its spatial and temporal location, the authors propose to distinguish three successively developing phases of such a model, which will include all of the listed manifestations:

The first phase is preparatory or emotional-motivational with the inclusion of emotional, motivational and value-semantic aspects of engagement. Here, a kind of setting is created to be involved and to involve the partners in the activity.

The second phase is active or cognitive-behavioral, which includes cognitive (with its direct and indirect forms), behavioral, activity, socio-psychological and dialogic manifestations with their psychological mechanisms.

The third phase is evaluative and correctional, where the assessment of the completeness (complete, partial, absent) and dominance of any aspect of engagement is determined and its subsequent correction by the teacher. An expert assessment of the preparatory and active phases of engagement is carried out according to the principle: Ahigh level of severity, B-medium, C-low. The decision on the correction is made by the teacher, taking into account the grades received or the students' self-assessments. Possible combinations of assessments for making a decision on correction: $\mathrm{AA}, \mathrm{AB}, \mathrm{VA}, \mathrm{AC}, \mathrm{CA}$, BB, VS, SS, SV.

In the context of educational activities, there are two possible options for implementing the model of engagement: long-term and short-term. The long-term option is carried out by the teacher taking into account the cognitive and creative perspective of the student during the preparation, joint discussion and implementation of scientific and technological projects: science report, thesis, dissertation, joint report. Assessment of the level of engagement: qualitative, expert. It is determined by the level of the student's creative achievement and it is presented in the approved method of Scaffolding (L.M. Popov and P.N. Ustin [30]), through the components: I want-I can-I act.

The short-term option is carried out in the extremely compressed time of interaction between the teacher and the student (no more than 10 seconds), where the main result is the engagement of students in mastering the material assessed by the teacher. Here, the digital monitoring system "Examus" records the concentration of attention, the emotional response. The information and analytical system "Examus" is created on the basis of a 
neural network trained to instantly analyze information about the facial expressions and pantomimes of a person who is at the monitor, and to determine his emotions and attention by the characteristics of facial expression and behavioral reactions. The experimental results obtained by this method will be used to identify markers of increasing engagement with subsequent work on improving the effectiveness of digital monitoring using the described system "Examus" and to identify psychological mechanisms for managing and self-managing student engagement in educational activities in a digital environment.

To solve the problem of determining strategic approaches to create the effect of engagement in the joint activities of the teacher and the student, we take the following position: verbs as a representation of the action, much better convey the essence of each strategy than nouns. We believe that the strategies and intentions of the teacher and students should be aimed at achieving a "useful" result for both parties, when involvement in joint activities becomes a real reflection of their educational interaction. In this case, the internal and external actions of the participants can be conveyed by three verbs, each of which characterizes the strategic choice of each party, their typological characteristics and the probabilistic level of engagement. The teacher's actions can be conveyed through such verbs as: learn, attach, encourage. So we have three main strategies of teacher.

Learn ("Learning strategy") - means to provide educational information, the purpose, the conditions of activity, including attendance, requirements for completing tasks in the current period, the criteria for evaluating the exam (test). It is assumed that this is how the authoritarian teacher acts, and his exactingness to strictly fulfill the conditions creates, at best, forced involvement, which is what the assimilation strategy means.

Attach ("Attaching strategy") - involves the desire and ability of the teacher to interest students in the material, their personality, the technology of work, the use of audio-videotext material, when its development is stimulated by the actions of the senses. It is carried out to join the professional community, the formation of a professional identity. Type of teacher: democratic, with feedback opportunities, which contributes to the emotional and professional nature of engagement.

Encourage ("Encouraging strategy") - it means to stimulate the search activity of students for individual or joint finding of answers to existing problems of science and practice within the framework of the studied discipline. If at the same time the "meeting" of the teacher and the student took place, then the consequence of this is: the maximum concentration of attention, the transition from voluntary to post-voluntary attention; the manifestation of efforts for the redistribution of the required; the deployment of proactive actions for creative activity in the form of professional and personal growth, the production of "contribution" to the scientific, practical solution of the problem. Teacher type: creative. The nature of engagement: cognitive-creative.

The actions of students and their corresponding strategies can be conveyed by verbs: "perform", "professionally enrich", "self-actualize". To perform ("Performing strategy") is the action of a significant part of the students who are accustomed from school to obey the requirements of authoritarian teachers and to obey the requirements of parents at home those who know "better" how to live and what to do. Student type: performer. The engagement is either absent or forced.

To professionally enrich ("The strategy of a professional") means to have the position of a pragmatic student who seeks to fully master the knowledge of those academic disciplines that form the professional competence of a specialist. Priority is given to special disciplines, through the mastery of which professional identity is achieved and social and financial success can be achieved. Student type: professional performer. Engagement is cognitive in nature.

Self-realization ("Creative personality strategy") is a strategic position on the selective involvement of the student in interaction with the teacher. The condition for the 
manifestation of such involvement is the ability of the teacher not so much to convey the knowledge of the subject in a deep and reasoned way, but rather to reveal the unresolved problems inherent in this field of science, to acquaint students with different points of view on the problems. There may be an invitation to a dialogue on the terms of an equal partnership, an invitation to joint research activities or to the creation of author's projects. The type of student is the creator, and inclusiveness can be described as long-lasting and deep.

In both cases, we have three actions, three strategic positions of the interacting parties, according to their probabilistic actions. Engagement in the conditions of educational activity arises as an actor-actor interaction with the effect of oncoming movement. At the same time, we can assume the onset of full or partial involvement and the absence of such. In the course of classes, when the initiator of the "meeting" is the teacher, you can build the following combinations with an indication of the degree of engagement in the interaction "Teacher-Student":

The first combination. The authoritarian type of teacher (the requirement is to learn) seeks to involve students of all types. It can fully involve a student with a performing strategy, partially involve a professional, and cannot involve a creative student.

The second combination. A teacher of the democratic type can fully involve a student with the position of a professional and partially involve students with the positions of a performer and a creator.

The third combination. A creative-type teacher will fully involve the creative student and may partially involve students with a professional-type position, but cannot involve a performing student who is accustomed to unambiguous requirements and "problem-free" knowledge.

\section{Conclusions}

The result of theoretical analysis gives an idea of the spatial breadth of the aspects of the actors' engagement in the activity: cognitive, emotional, behavioral, motivational, sociopsychological, and physical. We propose to combine the spatial breadth of these aspects into three phases according to the criterion of the time sequence of the phenomenon of engagement: preparatory (emotional-motivational), active (cognitive-behavioral) and evaluative-correctional. As a result, a spatial-temporal model of engagement of participants of educational activity is built, which is the result of productive interaction between the teacher and the student in the short and long term.

Funding: The reported study was funded by RFBR, project number 20-04-60201.

\section{References}

1. E. Klinger, Consequences of commitment to and disengagement from incentives, Psychological Review, 82(1), 1-25 (1975)

2. L.I. Sokolova, E.S. Mishchenko, S.V. Ponomarev, Formirovanie podsistemy izmereniya $i$ analiza udovletvorennosti $i$ vovlechennosti personala $v$ processy $i$ sistemy menedzhmenta kachestva obrazovatel'noj organizacii, Formation of a subsystem for measuring and analyzing the satisfaction and involvement of personnel in the processes and quality management systems of an educational organization (2009)

3. M. Yu. Kondratiev, Social'naya psihologiya $i$ obshchestvo, Social psychology and Society, 6(3), 174-188 (2015) 
4. A.M. Kustubaeva, A.T. Kamzanova, Teoreticheskaya i eksperimental'naya psihologiya, 6(2), 6-13 (2013)

5. A.B. Bakker, Y. Wang, Self-undermining behavior at work: Evidence of construct and predictive validity, International Journal of Stress Management, 27(3), 241-251 (2020)

6. J.W. Newstrom, Organizational behavior: human behavior at work (2015)

7. C. Truss, R. Delbridge, K. Alfes, A. Shantz, E. Soane, Employee Engagement in Theory and Practice (2013)

8. T.Y. Bazarov, Organizacionnaya psihologiya, 9(4), 226-237 (2019)

9. A. Hollingshead, P. Williamson, C. Carnahan, Research and Practice for Persons with Severe Disabilities, 43(4), 269-284 (2018)

10. K. Xie, V.W. Vongkulluksn, L. Lu, S.L. Cheng, A person-centered approach to examining high-school students' motivation, engagement and academic performance, Contemporary Educational Psychology, 62 (2020)

11. R. Böheim, T. Urdan, M. Knogler, T. Seidel, Student hand-raising as an indicator of behavioral engagement and its role in classroom learning, Contemporary Educational Psychology, 62 (2020)

12. B.D. Jones, D. Carter, Relationships between students' course perceptions, engagement, and learning, Social Psychology of Education, 22(4), 819-839 (2019)

13. S.R. Harper, S.J. Quaye, Student Engagement in Higher Education (2008)

14. W.A. Kahn, E.D. Heaphy, Relational contexts of personal engagement at work in Employee Engagement in Theory and Practice (2013)

15. N.V. Kiseleva, Psihologiya i Psihotekhnika, 4, 74-81 (2017)

16. K. Fujiwara, Development of a school engagement scale for junior high school students, The Japanese Journal of Psychology, 91(2), 125-132 (2020)

17. B. Regueiro, J.C. Núñez, A. Valle, I. Piñeiro, S. Rodríguez, P. Rosário, Motivational profiles in high school students: Differences in behavioural and emotional homework engagement and academic achievement, International Journal of Psychology, 53(6), 449-457 (2018)

18. J. Reeve, S.H. Cheon, H. Jang, How and why students make academic progress: Reconceptualizing the student engagement construct to increase its explanatory power, Contemporary Educational Psychology, 62 (2020)

19. N.A. Smith, J.L. Brown, T. Tran, C. Suárez-Orozco, Parents, friends and immigrant youths' academic engagement: A mediation analysis, International Journal of Psychology, 55(5), 743-753 (2020)

20. M. McAllister, Predictive genetic testing and beyond: A theory of engagement, Journal of Health Psychology, 7(5), 491-508 (2002)

21. K. Shaw, An engagement strategy process for communicators, Strategic Communication Management, 9(3), 26-29 (2005)

22. E.R. Kahu, K. Nelson, Student engagement in the educational interface: understanding the mechanisms of student success, Higher Education Research and Development, 37(1), 58-71 (2018)

23. A. McCulloch, V. Kumar, S. van Schalkwyk, G. Wisker, Excellence in doctoral supervision: an examination of authoritative sources across four countries in search of performance higher than competence, Quality in Higher Education, 22(1), 64-77 (2016) 
24. Y.-F. Chang, B.-L. Cherng, The relations of teachers' teaching emotion, students' achievement emotion, and students' motivational engagement for junior high school students, Bulletin of Educational Psychology, 49(1), 113-136 (2017)

25. W.-W. Chen, C.-C. Chen, C.-L. Dai, U.N. Man, L. Cheng, Is the incremental theory of intelligence a key to students' motivational engagement? The moderating effects of self-enhancement and self-criticism, Interactive Learning Environments, 26(6), 730744 (2018)

26. T.O. Solomanidina, V.G. Solomanidin, Motivation of labor activity of personnel (2009)

27. M.I. Magura, Personnel Management, 11, 20-27 (1998)

28. E.G.T. Becerra, V. Reynoso-Alcántara, Social engagement as a measurement of cognitive reserve and how it relates to different cognitive skills in college students, Acta Colombiana de Psicologia, 22(2), 230-240 (2019)

29. R.L. Altman, B. Laursen, D.S. Messinger, L.K. Perry, Validation of continuous measures of peer social interaction with self-and teacher-reports of friendship and social engagement, European Journal of Developmental Psychology, 17(5), 773-785 (2020)

30. L.M. Popov, P.N. Ustin, Cognitive-behavioral concept and the possibilities of its implementation in the life activity of students, Psychological Journal, 42(1), 26-35 (2021)

31. A.W. Astin, Student involvement: a developmental theory for higher education, Journal of College Student Personnel, 25(4), 297-308 (1984)

32. V.M. Bekhterev, Psyche and life (2012) 